\title{
Methods in Enzymology, Vol. 479, Functional Glycomics
}

\author{
(M. Fukuda (ed.), Elsevier, Amsterdam-Boston-Heidelberg-London-New-York-Oxford-Paris, \\ 2010, 447 p., \$182)
}

DOI: $10.1134 / \mathrm{S} 0006297911100154$

This book consists of 23 chapters written by an international group of authors. The volume covers new development in glycosciences including functional studies of glycosylation in stem cells, functions revealed by gene knockout mice, glycan defects in muscular dystrophy, and glycans in tumor formation.

Chapters 1-3 highlight $\beta 1$,4-galactosyltransferase V as a growth regulator in glioma, roles of polysialic acid in migration and differentiation of neural stem cells, and structural and functional analysis of chondroitin sulfate proteoglycans in the neural stem cells.

Chapters 4-8 are devoted to analysis of transcription in stem cells, their movement, functional analysis of molecular chaperone Cosmc, 3-O-glycans as essential components of the intestinal mucus barrier, and tumor suppressors.

Chapters 9-12 present data about characterization of mice with targeted deletion of the $2 \beta 1,6-\mathrm{N}$-acetylglucosaminyltransferase-2, analyzing physiological function of polypeptide GalNAcT-1-deficient mice in humoral immunity and b3GnT2-deficient mice suffering due to deficiency of a major polylactosamine synthase, and the role of $\mathrm{N}$-acetylglucosaminyltransferase IVa in insulin secretion.

Chapter 13 characterizes the Ashwell-Morell receptor (AMR) of hepatocytes, originally termed the hepatic asialoglycoprotein receptor. AMR is the first cellular receptor to be identified and isolated and the first lectin to be detected in mammals. Clearance by liver AMR is enhanced by exposure of terminal galactose on the glycan chains.

Chapters 14 and 15 highlight roles of GlcNAc-6-Osulfotransferases in lymphoid and non-lymphoid tissues and core $\mathrm{O}$-glycans required for lymphocyte homing.

Chapters 16-19 summarize immunohistochemical analysis of carbohydrate antigens in chronic inflammatory gastrointestinal diseases and genetic defects in muscular dystrophy including various types of mutations.

Chapters 20-23 contain data about cellular and molecular characterization of abnormal brain development in protein $\mathrm{O}$-mannose- $\mathrm{N}$-acetylglucosaminyltransferase 1 knockout mice, human $L A R G E$ genes, a tumor suppressor function of laminin-binding $\alpha$-dystroglycan, and tumor formation assays.

The book contains author and subject indexes, a bibliography for each chapter, and also color photographs placed at the end of the book.

Like the previous Vol. 478, the book is very informative, and is novel both in terms of problems discussed and also new methods used for glycobiology.

This book will be very useful to a wide variety of readers from graduate students, researchers in academia, in industry, and to those who teach glycobiology and glycosciences at various levels. 